\title{
Comparison of Static Balance among Cricket, Badminton, Football and Track and Field Athletes
}

\author{
Aishwarya Dilip Sanghavi ${ }^{1}$, Khushboo Trishant Chotai ${ }^{2}$, Smita Chandrakant Patil ${ }^{3}$, \\ Amrutkuvar Shivaji Rayjade ${ }^{4}$, Janhavi Mahadev Sawant ${ }^{5}$
}

1, 2, 3, 4, 5 Department of Physiotherapy, Krishna College of Physiotherapy, Karad, Satara Maharashtra, India.

\section{ABSTRACT}

\section{BACKGROUND}

The balance plays an indispensable role in many sports. Static balance is crucial for a postural control and has an exceptional effect on the performance of sports players and for injury prevention. Sports like cricket, football, track and field, and badminton requires static balance for the execution of a sports-specific skill. Single leg stance test was used to assess balance on a surface during a $30 \mathrm{sec}$ single-leg standing posture with eyes open and eyes closed. The main goal of this study was to determine that, in which sport the static balance was more and in which sport the static balance was inferior. The objectives were to assess the static balance in cricket, badminton, track and field, football athletes and compare the static balance in all 4 sports [cricket, badminton, track and field, football]

\section{METHODS}

A total of one hundred and twenty - four athletes [124], cricket $\{\mathrm{N}=31\}$, football $\{\mathrm{N}$ $=31\}$, badminton $\{\mathrm{N}=31\}$, track and field $\{\mathrm{N}=31\}$ voluntarily participated in the study. Static balance was assessed by using single leg stance test with eyes open and eyes closed.

\section{RESULTS}

By comparing all sports, it showed that there was a statistically significant difference between cricket, football, badminton and track and field athletes in dominant and non - dominant leg with eyes open and eyes closed. With eyes open, a static balance was demonstrated superior in track and field followed by football, cricket and least in badminton players in the dominant leg and non-dominant leg. $(\mathrm{P}<0.0001)$ Whereas, with eyes closed, comparing between sports individually, there showed no such significant difference between dominant and non-dominant leg. Static balance was superior in track and field followed by football, by cricket and least in badminton in dominant and non-dominant leg $(\mathrm{P}<0.0001)$.

\section{CONCLUSIONS}

Track and field players did not differ in dominant and non-dominant legs. In contrast, badminton players displayed mediocre static balance with eyes open and football players displayed mediocre static balance with eyes closed. There was no significant difference between open and closed eyes. But the balance score showed superior balance in open eyes when compared with closed eyes.

\section{KEY WORDS}

Athletes, Static Balance, Single Leg Stance Test, Balance, and Sports Performance.
Corresponding Author: Dr. Khushboo Chotai, Department of Physiotherapy, Krishna College of Physiotherapy, Karad, Satara,

Maharashtra, India.

E-mail: sanghavitina830@gmail.com

DOI: $10.14260 / \mathrm{jemds} / 2021 / 594$

How to Cite This Article:

Sanghavi AD, Chotai KT, Patil SC, et al. Comparison of static balance among cricket, badminton, football and track and field athletes. J Evolution Med Dent Sci 2021;10(34):2915-2919, DOI: 10.14260/jemds/2021/594

Submission 20-04-2021, Peer Review 24-06-2021, Acceptance 30-06-2021, Published 23-08-2021.

Copyright (C) 2021 Aishwarya Dilip Sanghavi et al. This is an open access article distributed under Creative Commons Attribution License [Attribution 4.0 International (CC BY 4.0)] 


\section{BACKGROUND}

An individual's ability to balance is influenced by some external and internal factors. Internal factors include the visual system, vestibular system, and sensory information obtained from the somatosensory system and external factors like strength, flexibility, coordination etc. If there exists any issue in any of these factors, it may lead to balance issues and perhaps increases the risk for injuries. ${ }^{1}$ Independent of these factors, static and dynamic balance continues to be an essential motor skill because it is at the centre of all human movements.

Balance can be assessed statically and dynamically. In sports, an athlete requires balance either in the static or dynamic position which helps to protect from acute or overuse injuries. ${ }^{2}$ Balance exercises are often prescribed to enhance postural control and perhaps reduce the risk of acute or chronic injury. What seems to be lacking from this line of research is that how athletes from different sports perform on static balance tests.

Every sport has common activities like cutting, running, jumping, which majorly impose injury risk at lower extremities. Impaired stability and balance can be found in these sports-specific movements. ${ }^{2}$ The research suggested that balance impairments have been one of the risk factors for injuries in sports. Many authors suggested that a decrease in static balance is a risk factor for many injuries in sports.

With this research study, balance exercise can be prescribed more effectively to athletes from different sports. Static balance assessment is a key factor in the development of the sensory-motor system. ${ }^{2}$ Static balance can be evaluated by having a player maintain the motionless position while standing on one or both legs. ${ }^{3}$

Each sport requires a different level of sensory-motor process to perform skills. Basketball is one such popular sport wherein, the players need to change the direction swiftly, dribble the ball from one end of the court to the other, jump to make a basket, and defend the ball from opposite teams. Football requires skills such as ball controls, dribbling skills, passing accuracy, and body control.

Cricket, football and track and field sports have common activities like running, jumping activities. A specific activity differs in every sport like cricket is a popular sport that requires a wide range of physical activity. Cricket includes running, throwing, batting, and bowling, catching, and diving. Balance is important in cricket for pace bowlers and batsmen. It is important for bowlers as they need to keep upright when running into a bowl as the upright position helps aim and gather momentum to bowl with. If the batsmen are falling over a little bit, due to some balance issues, they won't be in a comfortable zone, as the ball would keep hitting the pad. Track and field athletics is a collection of sports events that include running, jumping, and throwing. To coordinate with all these movements balance is important. Cricket requires three skills i.e., batting, bowling, and fielding which requires good muscular endurance. ${ }^{5}$

However, the argument exists whether high-level athletes demonstrate different positional strategies (eyes open or closed) compared with others competing in different sports. ${ }^{4}$ Indeed, there is a lack of research evidence regarding whether balance assessment with eyes closed is more efficient than tests with opened eyes. ${ }^{4}$
Although, we hypothesized that a postural control would be different among the athletes in these sports. An appreciation may give an insight into whether sport demands influence a balance and may help sports physiotherapists who prescribe the balancing exercise more effectively.

Till now, the study of comparing static balance between sports does not exist. There are numerous tests to assess the static balance test ${ }^{3}$. For static balance, there is a single-leg stance test, balance error scoring system, flamingo balance test.

Among all static balance tests, the single-leg stance test is more sensitive. The reliability of the test according to the recommendations of Fleiss is 95 IC for ICC between $0.4-0.75$ that indicates good reliability, while a value of above 0.75 is indicative of excellent reliability [intra-rater test reliability $0.67-0.96]$. An accurate measurement or balance is important for injury prevention, rehabilitation as well as the finest sports performance. Studies comparing the balance abilities among the athletes competing in different sports do not exist. Therefore, our purpose of the study was to compare the static balance amongst cricket, badminton, football, and track and field athletes.

\section{METHODS}

This was an observational study conducted among 124 participants, age ranged between 18 and 25 years. The study was done from November 2019 to April 2020. The selection of participants was done by a prevalence-based sample method using the simple random sampling method. (Cricket, $\mathrm{N}=31$; football, $\mathrm{N}=31$; basketball, $\mathrm{N}=31$, and track and field, $\mathrm{N}=31$ ) The participants were considered according to the inclusion and exclusion criteria. The total sample size was 132 but we got 124 sample sizes i.e., 31 sample sizes in each group due to covid crisis and time.

\section{Inclusion Criteria}

1. All the individuals with inclusion criteria of age group 18 - 25 years were included in this study; sports included cricket, badminton, football and track and field athletes;

2. Both male and female athletes.

3. Participants had to be currently competing in only one sport for the previous 3 years and the athletes willing to participate.

\section{Exclusion Criteria}

1. Participants were excluded if they had visual problems, pain in the last 3 months, low back pain, vestibular problems, and lower extremity injuries such as ankle sprain, meniscal injuries, etc.

2. Participants who were not willing to participate were excluded.

Materials used were inch tape, chalk, stopwatch, white athletic tape, plinth, and paper.

\footnotetext{
Formula

$\mathrm{n}=\left(\mathrm{SD}_{1}^{2}+\mathrm{SD}_{2}^{2}\right) \times 7.84\left(\mathrm{M}_{1}-\mathrm{M}_{2}\right)$

$\mathrm{n}=$ sample size
} 
$\mathrm{SD}^{2}{ }_{1}=$ standard deviation of dominant limb balance scores

$=1.3$

$\mathrm{SD}^{2}{ }_{2}=$ standard deviation of non-dominant balance score

$=1.4$

$\mathrm{M}_{1}=$ mean score of the dominant limb

$=13.3$

$\mathrm{M}_{2}=$ mean score of non-dominant limb

$=11.6$

$(1.32+1.4) \times 7.8413 .3-11.6$

571.7

$\mathrm{N}=33.52$ (in each group as per budget and time)

$\mathrm{N}=33 \times 4=132$ samples.

Source - Bressel E, Yonker JC, Kras J, Heath EM. Comparison of static and dynamic balance in female collegiate soccer, basketball, and gymnastic athletes. Journal of athletic training. 2007 Jan; 42(1):42.

\section{Procedure}

Approval for the study was obtained from the protocol committee and the Institutional Ethical Committee of the KIMSDU. After the concern, the subject had been approached for the study. The procedure had been explained and written informed consent was taken from those willing to participate. Demographic information of the subjects was taken. Individuals were explained about the purpose and procedure of the study.

Each of them was assessed by a static balance test. Static balance was evaluated by using the single-leg stance test.

Then all the sports were compared to each other. And the experimental result was statistically analysed. A total of 131 athletes were grouped into 4 sports. (Cricket, football, badminton and track and field athletes) based on the inclusion and exclusion criteria. Informed consent was taken from the subjects; the patients were assessed by following: 6

A single-leg stance test had been performed with eyes open and closed. Subjects were made to stand on one leg with the other leg flexed. Arms were on the hips. The investigator had turned on the stopwatch and had to continue until the subject loses his balance or touches his foot on the floor. Then the time duration was recorded.7-10

The result of the study was done based on a detailed assessment.

\section{Outcome Measures}

Single leg stance test required participants to keep their hands on their hips, their eyes facing forward, and the foot of the non - testing, leg held at knee level. The test had been performed with eyes open and eyes closed.

The test was timed (in seconds) from the moment the participant got into the testing position until the foot touched the ground or arms were separated from the hips. The time record began when the opposite foot of leg support was lifted from the floor until the foot touched the other leg or ground.

At the start of the test patient was instructed to lift one leg with knee flexion, and retain this static single-leg stance for 30 seconds.

\section{Statistical Analysis}

Data analysis was performed using the Instat software (GraphPad Instat 3). ANOVA test was used to compare the mean of all the sports of both dominant and non-dominant legs. An unpaired t test was used to compare the specific sport between dominant and non-dominant leg.

\section{RESULTS}

This study compared static balance among cricket, football, badminton and track and field athletes. we hypothesized there is a significant difference between the four sports. Out of the total sample of 124 participants, 93 were males and 31 were females in the age group of 18 - 25 years. From our study, it was stated that there was a statistically significant difference between cricket, football, badminton and track and field athletes in dominant and non-dominant leg with eyes open and eyes closed.

With eyes closed, when ANOVA test was performed, by comparing all sports, it showed that there was a statistically significant difference between cricket, football, badminton and track and field athletes $(\mathrm{P}<0.001)$. When compared with individual sport, an unpaired t-test was used to compare the specific sport between dominant and non-dominant legs. Comparing cricket between dominant and non-dominant legs did not show a significant difference. Football sport when compared between dominant and non-dominant leg, showed no significant difference. Badminton and track and field sports when compared between dominant and non-dominant leg showed no significant difference. There was no significant difference between dominant and non-dominant legs with eyes closed.

\begin{tabular}{|c|c|c|c|c|c|}
\hline \multirow{2}{*}{ Sports } & \multicolumn{2}{|c|}{ Dominant Leg } & \multicolumn{2}{|c|}{ Non-Dominant Leg } & \multirow{2}{*}{ P Value } \\
\hline & Mean & SD & Mean & SD & \\
\hline Cricket & 60.87 & 30.002 & 27.32 & 10.28 & $\begin{array}{c}P<0.4561 \text { not } \\
\text { significant }\end{array}$ \\
\hline Football & 90.25 & 43.365 & 27.03 & 10.79 & $\begin{array}{l}\mathrm{P}<0.4746 \text { not } \\
\text { significant }\end{array}$ \\
\hline Badminton & 50.77 & 33.9 & 20.96 & 10.01 & $\begin{array}{l}P<0.4448 \text { not } \\
\text { significant }\end{array}$ \\
\hline Track and field & 98.35 & 38.003 & 34.83 & 10.495 & $\begin{array}{c}P<0.5307 \text { not } \\
\text { significant }\end{array}$ \\
\hline
\end{tabular}

\begin{tabular}{|c|c|c|c|c|c|}
\hline \multirow{2}{*}{ Sports } & \multicolumn{2}{|c|}{ Dominant Leg } & \multicolumn{2}{|c|}{ Non-Dominant Leg } & \multirow[b]{2}{*}{ P Value } \\
\hline & Mean & SD & Mean & SD & \\
\hline Cricket & 78.54 & 33.585 & 70.77 & 46.884 & $\begin{array}{l}\mathrm{P}<0.0001 \\
\text { extremely } \\
\text { significant }\end{array}$ \\
\hline Football & 122.12 & 117.9 & 101.5 & 107.53 & $\begin{array}{l}\mathrm{P}<0.0001 \\
\text { extremely } \\
\text { significant }\end{array}$ \\
\hline Badminton & 69.04 & 36.08 & 60.77 & 47.77 & $\begin{array}{l}\mathrm{P}<0.0001 \\
\text { extremely } \\
\text { significant }\end{array}$ \\
\hline Track and field & 186.36 & 98.705 & 171.09 & 91.864 & $\begin{array}{c}\mathrm{P}<0.0001 \\
\text { significant }\end{array}$ \\
\hline
\end{tabular}

With eyes open, comparison of dominant and nondominant legs in cricket, football, badminton and track and field athletes. It depicts that, there showed an extremely significant difference when compared with all sports by performing ANOVA test $(\mathrm{P}<0.0001)$. When compared with individual sport specifically between dominant and nondominant leg by unpaired t-test, it depicts that, there displays the extremely significant difference between dominant and non-dominant legs respectively. Comparing cricket between dominant and non-dominant legs showed an extremely 
significant difference. Likewise, football, cricket and track and field compared between dominant and non-dominant leg showed an extremely significant difference. The result showed an extremely significant difference between eyes open and eyes closed athletes. The overall knowledge of our study suggested that static balance with eyes closed displayed superior in track and field followed by football, then cricket and least in badminton players. Whereas, with eyes open, static balance displayed superior balance and mediocre in badminton players. Statistically, eyes open scores were more than eyes closed. Track and field athletes displayed most superior balance with eyes open and eyes closed and badminton displayed the most inferior balance between eyes open and eyes closed.

\section{DISCUSSION}

The study compared static balance amongst cricket, football, badminton and track and field athletes. We hypothesized that static balance scores would be different amongst athletes competing in different sports. ${ }^{3}$ The finding from this study suggests that there was a significant difference in static balance between cricket, football, badminton and track and field athletes. There also showed a significant difference between dominant and non-dominant legs according to sports. Approximately right-side dominance was exhibited in mobilising functions of the lower limb. ${ }^{6}$ We chose a younger study group, between 18 and 24 years of age; so, we had the best chance to find the balance issue.

In earlier research, they studied the difference in balance ability amongst different sports players. ${ }^{3}$ Although, the idea of sports involvement improving balance is not new, our study extends this knowledge to a particular sport and suggests that the specific sensory-motor challenges, rather than general sports activity, are important for the development of optimal balance. $^{3}$

Within our study, the statistical differences observed amongst sports may be related to unique sensory-motor challenges executed by each sport. With eyes closed, track and field displayed superior static balance than the football and cricket and least in badminton players. (Track and field $>$ Football $>$ cricket $>$ badminton). ${ }^{4}$ When compared static balance between DL and NDL leg according to various sports, there showed no such significant difference between DL and NDL. Cricket and badminton demonstrated inferior static balance compared with track and field and football players. Track and field may have superior balance in both DL and NDL as this sport is a collection of events that include running, jumping and throwing. These sports may develop superior attention focus on cues that alter the balance performance, such as acceleration, joint position and neuromuscular coordination. ${ }^{7}$

In contrast, football players have to perform lower extremity actions such as passing, shooting and dribbling skills during the match that requires maintaining a strong static balance when the individual hits the ball more with the dominant leg2. In contrast, to track and field and football, badminton players displayed the lowest balance score as it required twists, jumps and swings to strike the shuttlecock.
The static balance might be less developed than cricket, as supported by our study.

Cricket displayed less balance between the dominant and non-dominant legs. Statistically, the dominant score was more than non-dominant score. The reason may be due to less focus on balance training, or it may be due to sensorimotor challenges, or the single-leg stance test was not sensitive enough to pick up the differences. ${ }^{3}$ Raouf Hammami and colleagues compared the rugby, sprinters and jumpers' players. The study reported that sprinters and jumpers demonstrated inferior static balance compared with rugby players. ${ }^{4}$ Eadric Bressel and colleagues compared football, basketball and gymnast athletes. Studies showed that football athletes have greater balance compared to other sports due to good ROM, strength etc. ${ }^{3}$

Furthermore, with eyes open, static balance showed an extremely significant difference in DL and NDL between all four sports $(\mathrm{P}<0.0001)$. When compared to individual sports, track and field demonstrated superior balance than football than cricket and badminton players in DL and NDL limb. Specifically, there displayed an extremely significant difference between dominant and non-dominant legs between all four sports when compared individually. Eyes open score were more than eyes closed.

Static scores were not different between track and field and cricket, because there may be some sensorimotor challenges common in these 2 sports, or it may be that the single-leg stance test was not sensitive enough to pick up the difference. ${ }^{3}$

The specific changes in sensorimotor systems that result from athletic sports participation are complex. Some indirect evidence suggests the probability of detecting a change in joint position (proprioception) or biomechanical cues (joint acceleration) may be the contrivance for the change. Intuitively, enhanced balance training reduces the risk of some musculoskeletal injuries such as sprains, etc. ${ }^{8}$

In addition, an athletic trainer would benefit from knowing which athlete requires more balance training to reduce all musculoskeletal injuries. Following this study, we hoped to understand better that how to balance impact to various sports. ${ }^{3}$ However, according to our study, we observed that track and field sports displayed more superior balance than other sports and badminton displayed the most inferior balance compared with other sports. But we can't predict that the badminton sport requires more balance training as the sample size was less to convince the differences. ${ }^{8}$ The other reason may be, the single-leg stance test was not enough sensitive to pick up the differences.

Vuillerine and Nougier (2004) conducted tests on sports athletes (gymnasts, handball, football) while they were tested with three balances tests; one foot on a mat; one foot; both feet together. However, it was observed that gymnasts demonstrated better balance during eyes closed postural measurements. ${ }^{9}$ Megan Stanford and colleagues researched, whether balance with closed eyes is more efficient than training with open eyes in an elderly population. ${ }^{7}$ The individuals were assessed for balance training for over four weeks. There showed no significant difference between eyes open and eyes closed. The reason may be that, the elderly people can improve their balance in a small number of training sessions, the subject selection was relatively not appropriate as some elderly people were active and some had resided in 
retirement centres and also the population for this study was small. ${ }^{6}$

Following our study, it showed that there displayed no significant difference between DL and NDL in all four sports. A previous study done by Author Chloe Schorderet and colleagues; stated that balance performance is not influenced by leg dominance. 10 There showed no significant difference between dominant and non-dominant limbs. The study conducted unipedal balance test (eyes open and eyes closed). However, in this study, the authors showed that leg dominance does not influence balance performance. The difference may not be seen because, the balance is influenced by different parameters such as motor coordination, biomechanical components (strength and endurance) etc. ${ }^{10}$

\section{CONCLUSIONS}

We can state that static balance was demonstrated superior in track and field followed by football, cricket and the least in badminton players in the dominant leg and non-dominant legs with eyes open and eyes closed. In all four sports, the dominant leg showed a greater score than non-dominant leg.

\section{Limitations}

Few limitations should be noted. The sample size was less as we compared four sports with a limited population. Huge sample size was needed to improve the balance training sessions. The third limitation was that the professional players were not involved in the project for accurate results.

Data sharing statement provided by the authors is available with the full text of this article at jemds.com.

Financial or other competing interests: None.

Disclosure forms provided by the authors are available with the full text of this article at jemds.com.

\section{REFERENCES}

[1] Kilroy EA, Crabtree OM, Crosby B, et al. The effect of single-leg stance on dancer and control group static balance. International Journal of Exercise Science 2016;9(2):110-20.

[2] Rami P, Prabhakar MM. Comparison of static balance in male football and basketball players by using flamingo balance test. International Journal of Physiotherapy 2018;5(5):162-6.

[3] Bressel E, Yonker JC, Kras J, et al. Comparison of static and dynamic balance in female collegiate soccer, basketball, and gymnastics athletes. Journal of Athletic Training 2007;42(1):42-6.

[4] Hammami R, Behm DG, Chtara M, et al. Comparison of static balance and the role of vision in elite athletes. Journal of Human Kinetics 2014;41:33-41.

[5] Khuman PR, Kamlesh T, Surbala L. Comparison of static and dynamic balance among collegiate cricket, soccer and volleyball male players. International Journal of Health \& Allied Sciences 2014;3(1):9-13.

[6] Kiyota T, Fujiwara K. Dominant side in single - leg stance stability during floor oscillations at various frequencies. Journal of Physiological Anthropology 2014;33(1):1 - 9.

[7] Carpenter C, Stanford M, Putnam K. A comparison of eyes open versus eyes closed balance training. Thesis, Dissertations, and Capstone Projects. School of Physical Therapy, Pacific University 2001.

[8] Ambegaonkar JP, Caswell SV, Winchester JB, et al. Balance comparisons between female dancers and active nondancers. Research Quarterly for Exercise and Sport 2013;84(1):24-9.

[9] Vuillerme N, Danion F, Marin L, et al. The effect of expertise in gymnastics on postural control. Neurosci Lett 2001;303(2):83-6.

[10] Schorderet C, Hilfiker R, Allet L. The role of the dominant leg while assessing balance performance. A systematic review and meta-analysis. Gait \& Posture 2021;84:66-78. 